\title{
A-kinase anchoring protein 4 has a conserved role in mammalian spermatogenesis
}

\author{
Yanqiu Hu, Hongshi Yu, Andrew J Pask, Deborah A O’Brien", Geoff Shaw and Marilyn B Renfree \\ ARC Centre of Excellence for Kangaroo Genomics, Department of Zoology, The University of Melbourne, Melbourne, \\ Victoria 3010, Australia and ${ }^{1}$ Department of Cell \& Developmental Biology, University of North Carolina School of \\ Medicine, Chapel Hill, North Carolina \\ 27599-7090, USA
}

Correspondence should be addressed to M B Renfree; Email: m.renfree@unimelb.edu.au

\begin{abstract}
A-kinase anchor protein 4 (AKAP4) is an X-linked member of the AKAP family of scaffold proteins that anchor cAMP-dependent protein kinases and play an essential role in fibrous sheath assembly during spermatogenesis and flagellar function in spermatozoa. Marsupial spermatozoa differ in structural organization from those of eutherian mammals but data on the molecular control of their structure and function are limited. We therefore cloned and characterized the AKAP4 gene in a marsupial, the tammar wallaby (Macropus eugenii). The gene structure, sequence, and predicted protein of $A K A P 4$ were highly conserved with that of eutherian orthologues and it mapped to the marsupial X-chromosome. There was no AKAP4 expression detected in the developing young. In the adult, AKAP4 expression was limited to the testis with a major transcript of $2.9 \mathrm{~kb}$. AKAP4 mRNA was expressed in the cytoplasm of round and elongated spermatids while its protein was found on the principal piece of the flagellum in the sperm tail. This is consistent with its expression in other mammals. Thus, AKAP4 appears to have a conserved role in spermatogenesis for at least the last 166 million years of mammalian evolution.
\end{abstract}

Reproduction (2009) 137 645-653

\section{Introduction}

The sperm tail controls sperm motility and effective sperm delivery, and also aids in penetration of the oocyte which is essential for fertilization (Miki et al. 2002). It is made up of the connecting, middle, principal, and end piece. The principal piece occupies approximately three quarters of the length of the flagellum and acts as the main structure driving sperm motility. The fibrous sheath is a unique cytoskeletal structure surrounding the axoneme and the outer dense fibers in the principal piece of the flagellum and is largely comprised of A-kinase anchor proteins (AKAPs) and a sperm-specific isozyme of glyceraldehyde 3-phosphate dehydrogenase (GAPDHS; Bunch et al. 1998, Mandal et al. 1999, Vijayaraghavan et al. 1999, Brown et al. 2003). During sperm maturation and capacitation many changes occur including modification of the mitochondria matrix and the mid-piece differentiation necessary for motility in marsupials (Temple-Smith \& Bedford 1976). GAPDHS was identified as a conserved mammalian energy source for sperm motility in marsupials (Ricci \& Breed 2005). All of these data suggest that marsupials employ the same molecular strategies as eutherians during spermatogenesis.

$A K A P 4$, an $X$-linked member of the $A K A P$ gene family (Turner et al. 1998) encodes the most abundant protein of the sperm fibrous sheath in all mammals so far examined (Carrera et al. 1994, 1996, Fulcher et al. 1995, Turner et al. 1998, Colledge \& Scott 1999, Eddy et al. 2003). AKAP4 anchors CAMP-dependent protein kinase A (PKA) to the fibrous sheath of the spermatozoon where the kinase is likely to be required for the regulation of spermatozoal motility (Edwards \& Scott 2000, Brown et al. 2003). Its protein is restricted to the spermatogenic cells from the round spermatid stage until spermatozoa mature. Akap4 mRNA is expressed only in the postmeiotic phase of spermatogenesis (Miki et al. 2002). Since it is present only in germ cells and not in the somatic cells of the testis or in any other tissues (Fulcher et al. 1995), AKAP4 was thought to be a scaffold protein involved in regulating flagellum function (Miki et al. 2002). Akap4 deletion results in shorter sperm flagellum and an incomplete fibrous sheath formation causing infertility due to loss of motility (Miki et al. 2002). AKAP4 interacts with a number of other proteins in the fibrous sheath. One of these is AKAP3, another important component of the fibrous sheath (Mandal et al. 1999, Vijayaraghavan et al. 1999, Brown et al. 2003). In Akap4 null mice, the amount of AKAP3 was reduced both in testis and sperm (Miki et al. 2002) suggesting a functional link in the recruitment of these two proteins. 
GAPDHS is another major fibrous sheath protein that is essential for glycolysis providing an energy source for sperm motility. It is also distributed in the principal piece of the sperm flagellum (Bunch et al. 1998). While GAPDHS is present in Akap4 null mice, it does not accumulate in the flagellum (Miki et al. 2002). Therefore, sperm motility is still disrupted in the absence of Akap4 due to the interference with signal transduction and lack of association of glycolytic enzymes (Miki et al. 2002, Brown et al. 2003).

The fibrous sheath is a conserved structure that surrounds the outer dense fibers of the principal piece region of the sperm flagellum in both marsupial and eutherian mammals (Eddy 2007). Besides AKAP4, AKAP3 and GAPDHS, many other proteins are located on the flagellum. At least 17 major proteins have been identified in the fibrous sheath in rats (Kim et al. 1995b), 14 in humans (Jassim et al. 1992), and 10 in rabbits (Kim et al. 1995b, 1997). The amino acid composition of the purified fibrous sheath from human, rabbit, and rat spermatozoa are similar, indicating that mammalian sperm tail fibrous sheaths are composed of similar types of proteins (Kim et al. 1997). The outer dense fibers, another specific cytoskeletal component in mammals, encompasses the axoneme in the middle and principal pieces of the sperm tail, cooperating with the fibrous sheath to participate in signaling pathways to regulate sperm stability and motility. The genes that encode bovine and porcine outer dense fiber one proteins are highly conserved with those of human and rat (Kim et al. 1995a). In a marsupial (the brushtail possum Trichosurus vulpecula), there are seven major proteins in the outer dense fibers and 12 major proteins in the fibrous sheath (Ricci \& Breed 2001). There is also strong cross-reactivity to the brushtail possum fibrous sheath proteins in the principal piece of the koala Phascolartcos cinereus, the dunnart Sminthopsis macroura, and the tammar wallaby Macropus eugenii as well as in that of the rat (Ricci \& Breed 2001). Several other spermatozoon-specific proteins have been isolated from marsupial sperm. Two tammar sperm proteins, PSA-10 and WSA-1 (Harris \& Rodger 1998, 2005) are present on the acrosome, midpiece, and principal piece of mature spermatozoa but as yet nothing is known of their function (Harris \& Rodger 1998, 2005).

Although the 14 stages of spermiogenesis recognized in the tammar and sperm maturation follow a generally similar pattern to that of eutherians (Tyndale-Biscoe \& Renfree 1987, Harris \& Rodger 2005), the process in marsupials is complicated and dynamic and differs in some respects from that of eutherians (Lin et al. 1997). Sperm of most marsupials have a dorso-ventrally flattened nuclear surface (Temple-Smith 1994) and there is a more stable acrosome on the dorsal nuclear surface (Mate \& Rodger 1991, Sistina et al. 1993). During epididymal transit, changes in acrosomal morphology occur, and the sperm head rotates on its axis from a T-shape relative to the tail to become aligned with it (Temple-Smith 1994, Lin
\& Rodger 1999). Once in the female tract, the T-shape is resumed (Bedford \& Breed 1994). While the marsupial sperm head has become more compact but there is no special stability of chromatin in the nucleus by disulphide bonding or in its head membranes (Temple-Smith \& Bedford 1976, Cummins 1980), and although cAMP induces tyrosine phosphorylation of sperm proteins, it is not yet known whether capacitation occurs in marsupials (Sidhu et al. 2004). These differences in structural organization suggest that there may be differences in the genes controlling spermatogenesis and sperm function and motility. There has as yet been no study of the AKAP genes and proteins in marsupials. Given the importance of AKAP4 for sperm function in eutherian mammals, this study examined the conservation of $A K A P 4$ sequences in marsupials and a monotreme, and examined its expression during spermatogenesis in a marsupial, the tammar wallaby M. eugenii.

\section{Results \\ Cloning and characterization of the tammar AKAP4 gene}

An $\sim 2.5 \mathrm{~kb}$ partial AKAP4 cDNA sequence was obtained with cross-species primers from adult tammar testis cDNA. The full length cDNA was obtained with RACE. Sequence comparison with tammar partial genomic sequence (obtained from the trace archives at $\mathrm{NCBl}$; (http://www. ncbi.nlm.nih.gov/) confirmed the locations of all six exons, consistent with the genomic structure in human, mouse, and opossum. The full-length cDNA encodes a protein of 850 amino acids (Fig. 1) with exon 5 (the largest, about $2.2 \mathrm{~kb}$ ) encoding the mature protein (Fig. 2A).

Amino acid alignment demonstrates that AKAP4 is highly conserved among the mammals. The entire wallaby AKAP4 protein shares $93.4 \%$ amino acid similarity with opossum (another marsupial), 80.0\% with platypus (monotreme), $80.8 \%$ with human, $84.3 \%$ with mouse, $84.4 \%$ with rat, $86.7 \%$ with dog, $84.6 \%$ with cow, and $80.5 \%$ with horse. The cyclic AMP-dependent PKA plays a central role in sperm capacitation, motility and in the acrosome reaction. Two tethering domains of PKA, type $1 \alpha$ regulatory subunit $(R \mid \alpha)$, and type Il $\alpha$ regulatory subunit (RIl $\alpha$ ), are highly conserved in all AKAP4 proteins (Fig. 1). Protein tyrosine phosphorylation is one of the most important regulatory pathways to modulate events associated with sperm function, and conserved tyrosine sites have been found across all AKAP4 proteins (Fig. 1). Phylogenetic analysis with PHYLIP 3.63 groups AKAP4 proteins into the same three main clusters using three different methods (maximum-likelihood, maximum parsimony, and neighbor-joining; only neighbor-joining tree shown). Tammar wallaby AKAP4 clusters with the opossum and platypus, forming a non-eutherian group, rodents form another cluster while the other eutherian mammals form a third group (Fig. 2B). 


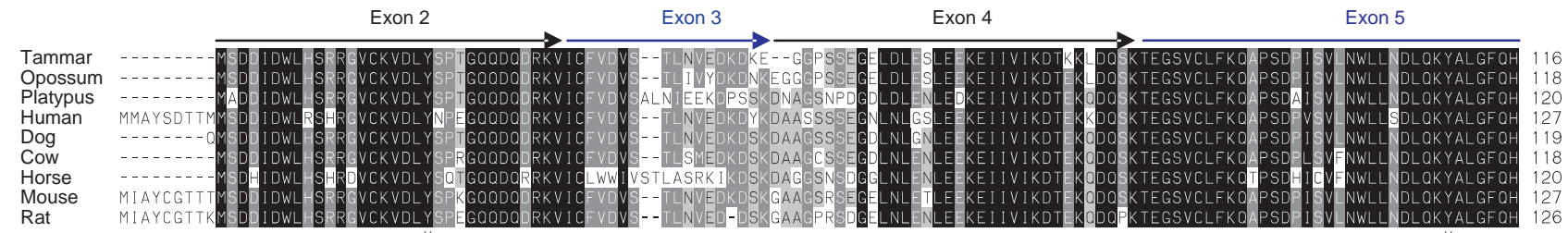

Exon 5

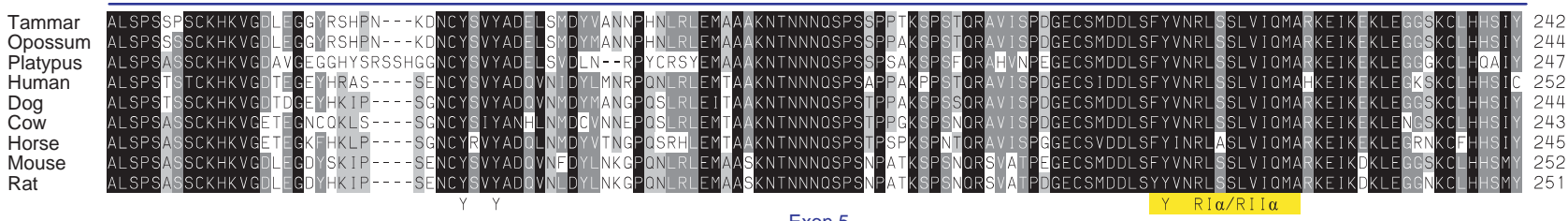

Exon 5

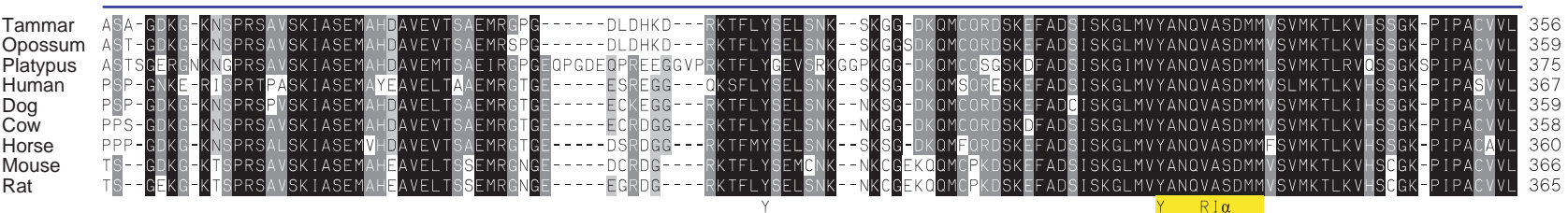

Exon 5

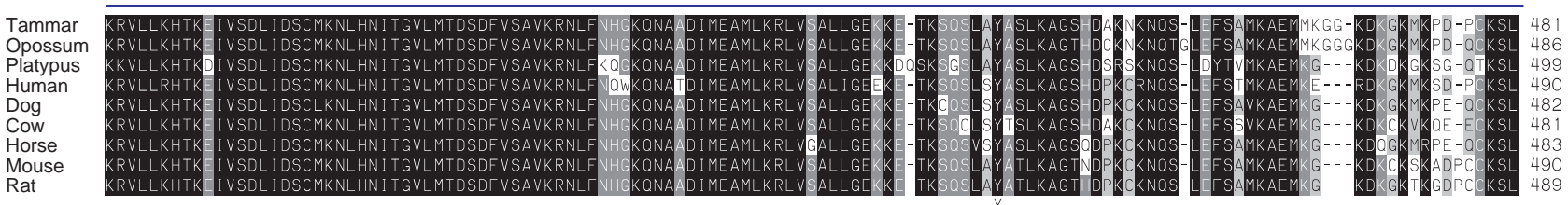

Exon 5

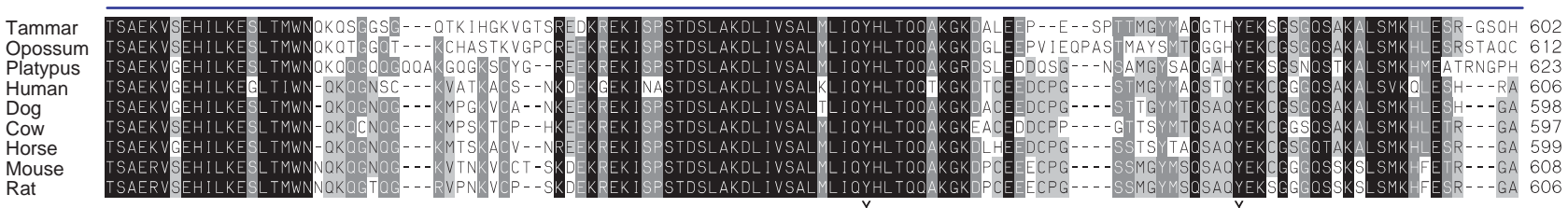

Exon 5
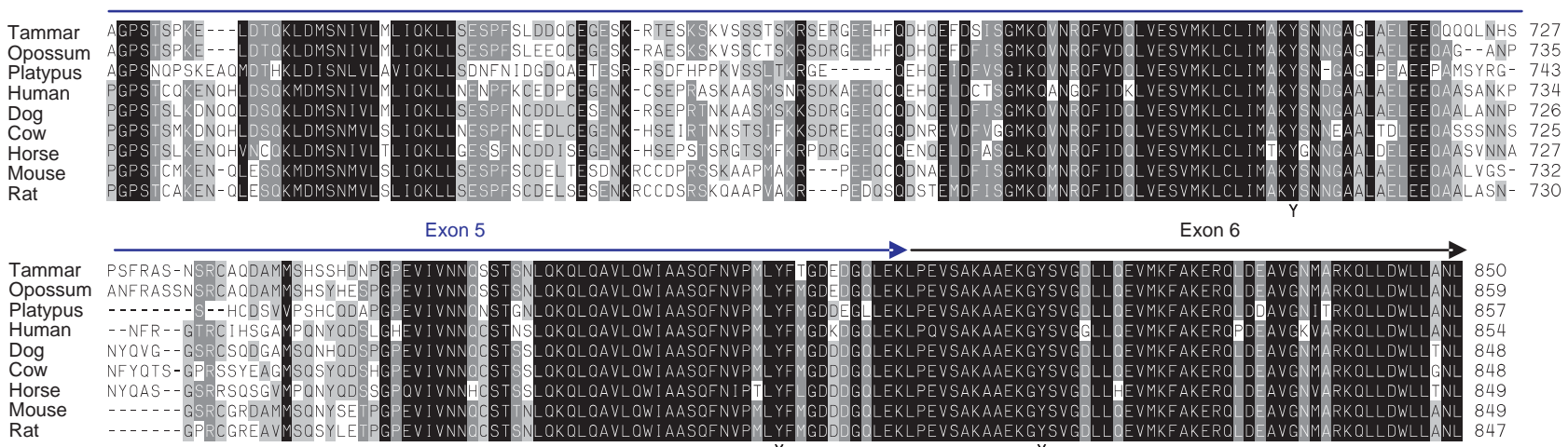

Figure 1 AKAP4 protein sequences alignment in known species. AKAP4 amino acid sequences were aligned with the wallaby predicted protein (ABL74506), opossum (XP_001363577), platypus (XP_001509793), human (NP_003877), dog (ENSCAFT00000025355), cow (NM_174235), horse (XP_001496170), mouse (Q60662), and rat (NM_024402). Regions shaded black indicate identical amino acids while those shaded in grey indicate similar amino acid residues. Protein encoded by the corresponding exons is shown for exons $2-6$ based on the tammar AKAP4 gene structure. Two conserved tethering domains of PKA, RI $\alpha /$ RII $\alpha$ and RI $\alpha$, are labeled with yellow blocks. Conserved tyrosine residues are marked with $\mathrm{Y}$.

AKAP4 was expressed in adult, but not developing testis

To determine the AKAP4 gene expression pattern in the tammar, RT-PCR was carried out in adult and developing testis with primers spanning the entire coding region. AKAP4 mRNA was detected strongly in adult testis and weakly in the epididymis from the caudal region but there was no expression in any other adult tissue (Fig. 3A). No signal was detected in developing testes at any stage of pouch young or juvenile development (Fig. 3B). No AKAP4 expression was detected in 


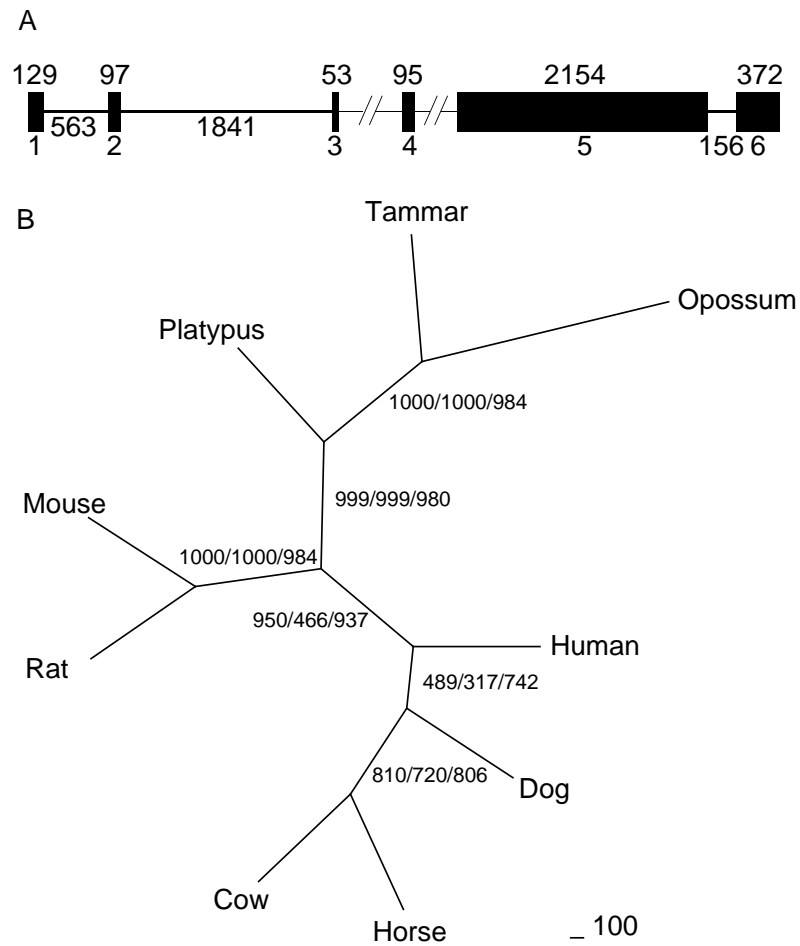

Figure 2 Tammar AKAP4 gene structure and protein phylogenetic analyses. A) The tammar wallaby AKAP4 gene consists of 6 exons. The black blocks represent the exons $1-6$ of $129,97,53,95,2154$, and 372 bp respectively. The sizes of intron 1 and 2 are 563 and 1841 bp respectively, but the size of introns 3 and 4 are unknown; intron 5 is 156 bp. B) AKAP4 phylogenetic tree constructed with PHYLIP 3.63 forms three clusters: a marsupial and monotreme group (tammar, opossum, and platypus), rodent group (mouse and rat) and other eutherian mammals (human, cow, dog, and horse).

epididymal sperm (Fig. 3B). Northern blotting analysis was used to quantitate the relative mRNA expression profile of AKAP4 in tammar wallaby. A primary transcript of $2.9 \mathrm{~kb}$ was present only in the testis, and not in the ovary, epididymis or any other somatic tissue examined (Fig. 3A). In addition, two smaller transcripts were detected, less than $1.5 \mathrm{~kb}$ in the testis, identical to that seen in mouse (Fulcher et al. 1995), the $2.9 \mathrm{~kb}$ hybridization band is consistent with predicted mRNA length and was taken to be the primary full-length transcript in tammar wallaby.

\section{AKAP4 $m R N A$ was detected in round and elongated spermatids}

To gain insight into the conserved role of the AKAP4 gene, we analyzed the gene expression pattern in adult testes by section in situ hybridization. Tammar AKAP4 mRNA was restricted to the germ cells (Fig. 4A) specifically at the round spermatid (Fig. 4D) and elongated spermatid (Fig. 4G) stage and mRNA was not detected in spermatogonia, spermatocytes (Fig. 4) or the principal piece of sperm tail (Fig. 4J). This implies that
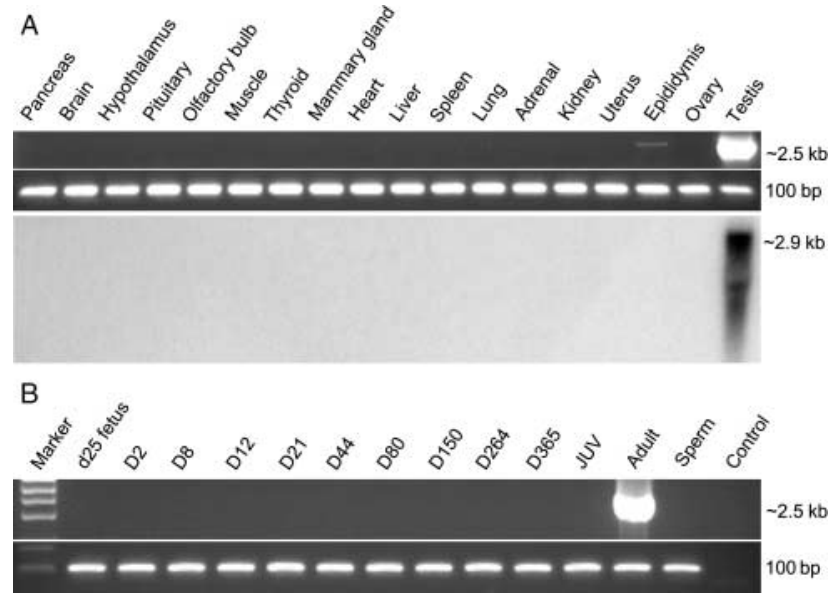

Figure 3 Tammar AKAP4 RT-PCR expression and northern blotting. A) Expression of the AKAP4 gene was assessed in a range of adult tissues. AKAP4 was strongly detected in adult testis and weakly expressed in the epididymis with RT-PCR $(\sim 2.5 \mathrm{~kb})$ (top) while only adult testis gave a predominant band of $2.9 \mathrm{~kb}$ with northern blotting (bottom). B) AKAP4 gene expression was profiled in developing testes and purified mature spermatozoa. AKAP4 was absent from developing testes from before birth until the juvenile state, while it was also absent from epididymal spermatozoa. 18S (100 bp) acted as a positive control.

AKAP4 expression begins post-meiotically. AKAP4 mRNA was predominantly cytoplasmic with some nuclear staining (Fig. 4D and G). There was no evidence of AKAP4 mRNA expression outside the tubules.

\section{AKAP4 protein was present in the sperm tail}

To further understand the role of AKAP4, we also investigated the protein distribution in adult testis by immunohistochemistry. Consistent with eutherian studies, very strong staining was observed on the mature spermatozoal tail and was undetectable in spermatogonia, primary spermatocytes, secondary spermatocytes, and round spermatids (Fig. 5A). However, there was some staining in the interstitial capillaries. Western blots were also conducted but yielded additional extra bands apart from the one of the expected size (82KB) (data not shown). Given this result, and the lack of AKAP4 mRNA staining anywhere else but in the seminiferous tubules, we conclude that the staining in the capillaries was an artifact due to non-specific binding.

\section{The AKAP4 gene is on the marsupial X-chromosome}

Gene mapping was performed to confirm that the location of AKAP4 in the genome was on the $\mathrm{X}$-chromosome as in all eutherian mammals so far examined. Tammar AKAP4 was mapped with fluorescent in situ hybridization (FISH) to the distal end of the long arm of the X-chromosome (Fig. 6). 


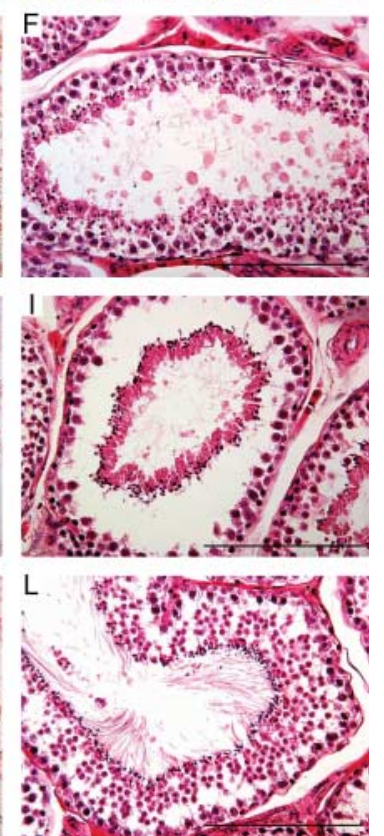

Figure 4 In situ hybridization of AKAP4 in the adult tammar testis. AKAP4 mRNA was detected largely in the cytoplasm of spermatids from the round to elongated stages up to the mature sperm stage. $\mathrm{A}, \mathrm{B}$, and $\mathrm{C}$ are low power $(\times 4)$ images while $\mathrm{D}, \mathrm{E}, \mathrm{F}, \mathrm{G}, \mathrm{H}, \mathrm{I}, \mathrm{J}, \mathrm{K}$, and $\mathrm{L}$ are high power $(X 40)$. D, E, F show a seminiferous tubule containing round spermatids (RS) $\mathrm{G}, \mathrm{H}$, I show a seminiferous tubule containing elongated spermatids (ES) and J, K, L show a seminiferous tubule with spermatozoa (SP) in the last row. The lefthand column shows sections incubated with antisense probe; the middle column shows negative controls with incubated with sense probe and the right-hand column provides standard hematoxylin \& eosin ( $\mathrm{H} \& \mathrm{E})$ stained sections. Scale bars $=100 \mu \mathrm{m}$.

\section{Discussion}

Despite the differences in structural organization of the marsupial and eutherian spermatozoon, it is clear that AKAP4 encodes a functionally important protein in spermatogenesis. The AKAP4 orthologues of the marsupial (tammar wallaby) and monotreme (platypus) were highly conserved with those of human and mouse and the expression patterns of tammar AKAP4 mRNA and protein had similar profiles to those of eutherians. AKAP4 was only detected in the adult testis of the tammar, and mRNA was observed only in round spermatids and elongated spermatids. The protein was also found in the sperm tail. This highly conserved expression pattern suggests that tammar AKAP4 is also the major structural protein of the fibrous sheath, tethering the regulatory subunits of PKA and other enzymes to organelles or cytoskeletal elements, and then initiating the signaltransduction pathways during sperm capacitation and motility (Fulcher et al. 1995, Miki et al. 2002).

AKAP4 encodes one of the most abundant proteins that form the sperm tail, so it is not surprising that it is highly conserved between tammar and human, mouse and rat. The full-length tammar AKAP4 gene was $2.9 \mathrm{~kb}$ comprising six exons and encoding a predicted protein of 850 amino acids. This is consistent with the gene structure of AKAP4 in all other mammals examined.
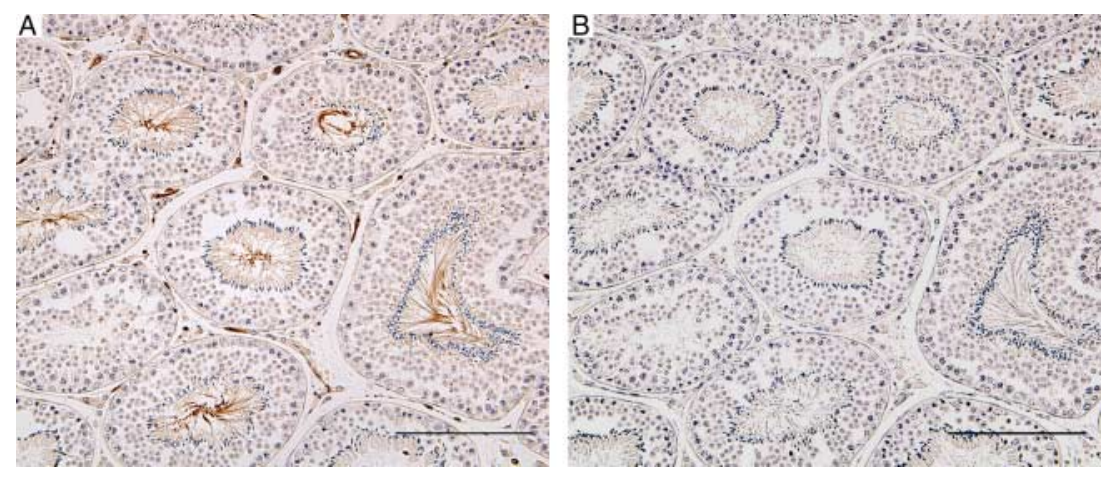

Figure 5 Immunolocalization of AKAP4 protein in the adult tammar testis. AKAP4 protein (brown staining) is mainly distributed in the principal piece of the sperm tail in tammar seminiferous tubules (A). There is also some staining in the interstitial tissue. The matching $\operatorname{lgG}$ negative control is shown on right panel (B). Scale bars $=$ $200 \mu \mathrm{m}$ 




Figure 6 Fluorescence in situ hybridization (FISH) of AKAP4. Hybridization signals (green) for wallaby $A K A P 4$ are localized to the distal end of the long arm of the X-chromosome (ChX). Only one chromosome pair was labeled per metaphase plate as the cells were derived from a male tammar (the Y-chromosome is indicated: ChY).

With the exception of the non-coding exon 1, all exons are highly conserved, especially exon 5, the largest exon whose coding sequence forms the majority of the AKAP4 mature protein. The difference of $\mathrm{N}$-terminus may reflect the species-specific protein or the different starting/splicing sites at $5^{\prime}$-end. Phylogenetic analysis grouped tammar AKAP4 most closely with that of another marsupial, the grey short-tailed opossum, and a distant relative from the South American marsupial fauna. In addition, we also aligned the major fibrous sheath protein from platypus, predicted to be AKAP4, and demonstrated that this gene is highly conserved in all mammal groups, and has been conserved for at least 166 million years. AKAP4 has not yet been isolated from any non-mammalian vertebrate groups. Mapping confirmed the localization of tammar AKAP4 on the marsupial X-chromosome as in eutherian mammals. This is consistent with the enrichment of genes involved in sex and reproduction on the mammalian X- chromosome (Ohno 1967, Wang et al. 2001). In the mouse, pro-AKAP4 (amino acids 1-840) is synthesized in the spermatids and then cleaved to form the mature AKAP4 protein (amino acids 180-840) before transported to the developing flagellum (Johnson et al. 1997, Nipper et al. 2006). In the tammar, the predicted pro-AKAP4 corresponds to amino acids $1-850$ while the mature AKAP4 is encoded by amino acids $180-850$ based on alignment with human and mouse. Tammar AKAP4 protein also has conserved functional regions including PKA binding sites and conserved tyrosine residues, suggesting conserved roles in both sperm motility and flagellum structure.
In humans and mice, AKAP4 is expressed exclusively in adult testis (Fulcher et al. 1995, Turner et al. 1998). Similarly, in the tammar, AKAP4 was only detected by RT-PCR in the adult testis and weakly in the epididymis. As expected, no expression was seen in the mature sperm. As sperm are stored in the epididymis, the weak band presumably reflects a small amount of residual mRNA that was shed into the seminiferous cord lumen and remains in the epididymis. Expression analysis in the developing testes from embryonic development through to adulthood demonstrated that the AKAP4 gene is only expressed in the mature (spermatogenic) testis and not in previous stages or in mature sperm. This is consistent with Akap4 expression in the mouse (Fulcher et al. 1995). Northern blotting confirmed this result showing a major transcript of $2.9 \mathrm{~kb}$ only in adult testis. The transcript length is as predicted for the tammar as well as similar to that of mouse and human. In situ hybridization demonstrated that AKAP4 expression was restricted to the germ cells, and the expression was tightly regulated in the spermatogenic cycle. AKAP4 transcripts were observed in round spermatids and terminated at the late-stage spermatids (stage 14; Lin et al. 1997). Strong expression was restricted to round spermatids and elongated spermatids. Therefore, the in situ hybridization results suggest that AKAP4 mRNA is present during the whole period of sperm transformation and sperm tail formation. The distribution of AKAP4 protein predominantly on the sperm tail suggests that it is involved in its formation.

Tammar AKAP4 protein distribution on the mature spermatozoal tail, especially on principal piece, is similar to that seen in mouse (Brown et al. 2003), inferring that it functions as a scaffold protein during spermiogenesis in tammar wallaby and by analogy with the mouse, in making sperm motility possible.

This is the first study to examine the AKAP4 gene in a non-eutherian mammal. Its conserved expression pattern and sequence similarity between eutherians, marsupials, and monotremes suggests that AKAP4 has not recently evolved its role in spermatogenesis, but has retained that function at least since mammals diverged from their mammal-like reptile ancestors. As predicted, mRNA distribution and protein localization do not overlap in the adult tammar testis. We have shown that AKAP4 mRNA is present in the round and elongating spermatids, where it is translated and pro-AKAP4 is likely cleaved to form the mature protein. Mature AKAP4 is then transferred to the principal piece of the sperm tail where it likely acts as a scaffold, regulating flagellum function. This pattern of expression is consistent with that in mouse and human (Mohapatra et al. 1998). Together, these results show a high degree of conservation of AKAP4 for over 148 million years of divergent mammalian evolution and clearly demonstrate that it acts as a critical X-linked component of mammalian spermatogenesis. 


\section{Materials and Methods}

\section{Animals}

Tammar wallabies M. eugenii from Kangaroo Island (South Australia) were maintained in open grassy yards in our breeding colony in Melbourne, Australia. Pouch young of various ages were removed from their mother's pouch for sampling. When the day of birth was uncertain, the age of pouch young was estimated using head length from published growth curves (Poole et al. 1991). All sampling techniques and collection of tissues conformed to Australian National Health and Medical Research Council guidelines (2004) and were approved by The University of Melbourne Animal Experimentation \& Ethics Committees.

\section{Tissues}

Tissues (brain, pituitary, hypothalamus, olfactory bulb, thyroid, muscle, spleen, heart, lung, liver, kidney, adrenal, mammary gland, uterus, and ovary) were collected from three adult females, and from two adult males (epididymides and testes). All tissues were collected under RNase-free conditions. Developing testes from three fetuses sampled 1-2 days before birth (d25) and from pouch young aged $\mathrm{d} 2(n=3), \mathrm{d} 8(n=3)$, $\mathrm{d} 12(n=2), \mathrm{d} 21(n=3), \mathrm{d} 44(n=3), \mathrm{d} 80(n=2), \mathrm{d} 150(n=1)$, $\mathrm{d} 264(n=1), \mathrm{d} 365(n=1)$, juveniles $(\sim 14$ months old $(n=3))$ (puberty/spermatogenesis in male tammar begins at around 19 months and males becomes fully mature at 25 months; Williamson et al. 1990) and mature adults $(n=2)$ for molecular analysis were snap frozen in liquid nitrogen and stored at $-80{ }^{\circ} \mathrm{C}$ until use. Mature sperm were collected from adult epididymides, in 1 X PBS and snap-frozen. Tissue for in situ hybridization was fixed overnight in $4 \%$ paraformaldehyde, washed several times in 1 X PBS, and stored in $70 \%$ ethanol before paraffin embedding and sectioning at $8 \mu \mathrm{m}$.

\section{Cloning of tammar AKAP4 and determining gene structure}

AKAP4 was initially cloned from adult testis by RT-PCR using cross species primers (AF1 and AR1) designed to conserved regions of the gene. The resulting $2475 \mathrm{bp}$ PCR product was then used to design tammar specific primers for $3^{\prime}$ RACE and $5^{\prime}$ RACE to fully characterize the AKAP4 transcript (the sequences of all primers are listed in Table 1).

Complementary DNA was reverse-transcribed from total RNA of adult testis of tammar wallaby, using the SMART cDNA library construction kit (Clontech). 5' RACE was performed using primer $5^{\prime}$ PCR and primer AR1. Owing to an incomplete coding sequence at the $5^{\prime}$ end, we designed a new primer AR2 as a nested primer according to the first sequence result and repeated 5' RACE. 3' RACE was performed using primer AF1 and CDS III nested PCR was performed using the AF2 and CDS III primers. PCR cycling conditions were: 35 cycles of $30 \mathrm{~s}$, $95{ }^{\circ} \mathrm{C} ; 60 \mathrm{~s}, 55^{\circ} \mathrm{C} ; 120 \mathrm{~s}, 72{ }^{\circ} \mathrm{C}$, in a $25 \mu$ reaction with GoTaq Green Master Mix (Promega), $0.4 \mu \mathrm{M}$ each.

To determine the tammar AKAP4 gene structure, comparative analysis was carried out using the gene structure of the human, mouse, rat, and South American grey short-tailed opossum Monodelphis domestica and the platypus
Table 1 Primers designed for analysis of AKAP4 expression by RT-PCR.

\begin{tabular}{|c|c|c|}
\hline Primers & Sequence $\left(5^{\prime} \rightarrow 3^{\prime}\right)$ & Function \\
\hline AF1 & TGTCTGATGATATTGACTGGTT & $\begin{array}{l}\text { Cross species } \\
\text { cloning \& } \\
\text { RT-PCR }\end{array}$ \\
\hline AR1 & TGGCAAACTTCATGACCTC & $\begin{array}{l}\text { Cross species } \\
\text { cloning \& } \\
\text { RT-PCR }\end{array}$ \\
\hline AF2 & TTTACGGGAGATGAGGATG & 3'RACE \\
\hline AR2 & AATAGGGTCCGAGGGTGCT & 5'RACE \\
\hline SMART IV & $\begin{array}{l}\text { AAGCAGTGGTATCAACGCA- } \\
\text { GAGTGGCCATTACGGCCGGG }\end{array}$ & $5^{\prime}$ RACE \\
\hline CDS III & $\begin{array}{l}\text { ATTCTAGAGGCCGAGGCGGCCGA- } \\
\text { CATG-d }(\mathrm{T})_{30} \mathrm{~N}_{-1} \mathrm{~N}(\mathrm{~N}=\mathrm{A}, \mathrm{G}, \mathrm{C} \text {, or } \mathrm{T} ; \\
\left.\mathrm{N}_{-1}=\mathrm{A}, \mathrm{G}, \text { or } \mathrm{C}\right)\end{array}$ & $3^{\prime}$ RACE \\
\hline $\begin{array}{l}5^{\prime} \mathrm{PCR} \\
\text { primer }\end{array}$ & AAGCAGTGGTATCAACGCAGAGT & $5^{\prime}$ RACE \\
\hline $18 \mathrm{~S} \mathrm{~F}$ & GATCCATTGGAGGGCAAGTCT & RT-PCR \\
\hline $18 \mathrm{~S} R$ & CCAAGATCCAACTACGAGCTTTTT & RT-PCR \\
\hline AF3 & GTGGCСТCTGACATGATGGT & BAC screen \\
\hline AR3 & GCGTTTCAGCATAGCCTC & BAC screen \\
\hline
\end{tabular}

$\mathrm{F}$ denotes forward primers, $\mathrm{R}$ denotes reverse primers. All primers are shown in the $5^{\prime}-3^{\prime}$ direction; CDSIII, Smart IV and $5^{\prime}$ PCR were synthesized by SIGMA (Genosys) according to the manual of the SMART cDNA library construction kit from Clontech.

Ornithorhyncus anatinus (http://www.ensembl.org/). Partial genomic sequence of $M$. eugenii was obtained from the trace archives at $\mathrm{NCBI}$ (http://www.ncbi.nlm.nih.gov/) to confirm the number of exons and the length of exons and introns.

\section{Alignment and phylogenetic analysis}

The AKAP4 protein sequences, human (NP_003877), mouse (Q60662), rat (NM_024402), cow (NM_174235), horse (XP_001496170), opossum (XP_001363577), and platypus (XP_001509793) were retrieved from GenBank (http://www. ncbi.nlm.nih.gov/). The sequence of dog (ENSCAFT0000002 5355) was retrieved from the Ensembl (http://www.ensembl. org/). The tammar AKAP4 (ABL74506) protein sequence has been submitted to GenBank. The above AKAP4 protein sequences were aligned with Clustal X 1.83 (http://www. clustal.org/), and edited by GeneDoc (http://www.nrbsc.org/ downloads/). The phylogenetic tree was constructed with the PHYLIP 3.63 program (University of Washington) using standard settings, maximum-likelihood, maximum parsimony, and neighbor-joining analysis with 1000 replicates, and viewed with TREE-view 1.6.6.

\section{RT-PCR expression analyses}

In order to check the expression pattern of AKAP4 in developing testis and adult tissues as well as mature sperm, total RNA was isolated using RNAwiz (Ambion Inc., Austin, TX, USA) according to the manufacturer's instructions. The quality and quantity of total RNA was verified by two methods, gel electrophoresis, and optical density reading with a Nanodrop (ND-1000 Spectrophotometer, Wilmington, USA). $2 \mu \mathrm{g}$ of total RNA was DNase-treated with DNase I (Ambion Inc.) for 30 min. $1 \mu \mathrm{g}$ of total RNA was reverse-transcribed using SuperScript III kit (Invitrogen). 
PCR was performed in a $25 \mu \mathrm{l}$ reaction with GoTaq Green Master Mix with $0.4 \mu \mathrm{M}$ of each primer (AF1 and AR1) and firststrand cDNA products. Amplification conditions were: $95{ }^{\circ} \mathrm{C}$ $30 \mathrm{~s} ; 55^{\circ} \mathrm{C} 60 \mathrm{~s} ; 72{ }^{\circ} \mathrm{C}, 120 \mathrm{~s}$ for 35 cycles (AKAP4), or 25 cycles (18S). Samples were analyzed on a 1.2 and $2 \%$ agarose gel for $A K A P 4$ and $18 S$ respectively.

\section{RNA isolation and northern blotting hybridization}

Total RNA was isolated from snap-frozen adult tissues with RNAwiz (Ambion Inc). The concentration and quality of total RNA were examined same as above. Equivalent amounts of RNA (about $12 \mu \mathrm{g}$ ) were subjected to electrophoresis in 1\% agarose gels containing formaldehyde (Sambrook et al. 1989). Northern blotting was performed according to standard methods, with hybridization at $42{ }^{\circ} \mathrm{C}$ in ULTRAhyb solution (Ambion Inc.) with $\left[\alpha_{-}{ }^{32} \mathrm{P}\right] \mathrm{dCTP}$-labeled cDNA probe (a 2475 bp DNA fragment representing the conserved AKAP4 domain was generated by the PCR), and autoradiographed at $-70{ }^{\circ} \mathrm{C}$.

\section{mRNA in situ hybridization}

For in situ hybridization to adult testes sections, antisense, and sense RNA probes were prepared separately from a region including AKAP4 domain ( $2.5 \mathrm{~kb}$ ) of the tammar wallaby and labeled with digoxigenin-UTP, using SP6 or T7 RNA polymerase (Sp6 for production of sense probe, T7 for antisense probe). Tissues were fixed in $4 \%$ paraformaldehyde overnight at $4{ }^{\circ} \mathrm{C}$, rinsed several times in $1 \mathrm{X}$ PBS, embedded in paraffin, sectioned onto polysine slides (Menzel-Gläser, Braunschweig, Germany). After de-waxing, the sections were washed several times with 1 X PBS, glycine, Triton X-100, and triethanolamine buffer, and then were immediately hybridized $\left(42{ }^{\circ} \mathrm{C}\right)$ and hybridization signals were detected by NBT/BCIP system according to the manufacturer's instructions (Roche Gmbh, Mannheim, Germany). $0.1 \%$ nuclear Fast Red (Aldrich Chemical Corp., Milwaukee, WI, USA) was used for counterstaining.

\section{Immunohistochemistry}

Tissue sections $(8 \mu \mathrm{m})$ were prepared as above and de-waxed. Antigen retrieved was performed in boiling $0.005 \mathrm{M}$ Tris-EDTA ( $\mathrm{pH}$ 9.0) for $20 \mathrm{~min}$, and treated with 3\% hydrogen peroxide in methanol for $15 \mathrm{~min}$. The AKAP4 primary antibody (rabbit antimouse, gift from Dr Edward M Eddy) was applied to tammar adult testis tissue sections used at $1: 150$ dilutions at $4{ }^{\circ} \mathrm{C}$ overnight. Signal was amplified using the ABC/HRP kit (DAKO, New South Wales, Australia), visualized with DAB (DAKO), and counterstained with hematoxylin.

\section{BAC library screening and chromosomal mapping}

To determine the chromosomal localization of AKAP4 in the tammar, a $M$. eugenii BAC library was screened with the AKAP4 2475 bp probe, used for the Northern blots. Membranes were pre-hybridized for $2 h$, the $\left[\alpha^{32} \mathrm{P}\right] \mathrm{dCTP}$-labeled probe was hybridized at $65{ }^{\circ} \mathrm{C}$ overnight. Filters were washed with $2 \times$ SSC/0.1\%SDS, $1 \times$ SSC/0.1\%SDS, $0.1 \times$ SSC/0.1\%SDS $10 \mathrm{~min}$ each at $65{ }^{\circ} \mathrm{C}$ and autoradiographed at $-70{ }^{\circ} \mathrm{C}$ for 2-5 days.

Chromosome preparations were made from peripheral blood according to standard methods with minor modifications (Schempp \& Meer 1983). Chromosome FISH was performed as previously described with minor modifications (Wilcox et al. 1996). The BAC genomic DNA was labeled with dUTPdigoxygenin (DIG) by nick translation at $14{ }^{\circ} \mathrm{C}$ for $1 \mathrm{~h}$ and pre-blocked with tammar wallaby Cot-1 DNA prior to hybridization. The probe was hybridized to tammar metaphase chromosome spreads at $37^{\circ} \mathrm{C}$ overnight. Hybridization was detected using mouse anti-DIG-FITC antibody (Serva, Heidelberg, Germany). After hybridization, the chromosome preparations were stained with DAPI (4, 6-diamidino-2phenylindole) to visualize the chromosomes.

\section{Declaration of interest}

There is no financial or other potential conflict of interest.

\section{Funding}

This study was supported by grants from the Australian Research Council: Centre of Excellence in Kangaroo Genomics and a Federation Fellowship to M B Renfree. A J Pask was supported by a National Health and Medical Research Council R D Wright Fellowship.

\section{Acknowledgements}

We thank all members of the wallaby research group and in particular Kerry Martin and Scott Brownlees for assistance with animals. We thank Sabeen Mapara for sharing partial Monodelphis domestica AKAP sequences early in this project and Dr E M Eddy for the kind gift of the AKAP4 antibody.

\section{References}

Bedford JM \& Breed WG 1994 Regulated storage and subsequent transformation of spermatozoa in the fallopian tubes of an Australian marsupial, Sminthopsis crassicaudata. Biology of Reproduction $\mathbf{5 0}$ 845-854

Brown PR, Miki K, Harper DB \& Eddy EM 2003 A-kinase anchoring protein 4 binding proteins in the fibrous sheath of the sperm flagellum. Biology of Reproduction $682241-2248$.

Bunch DO, Welch JE, Magyar PL, Eddy EM \& O'Brien DA 1998 Glyceraldehyde 3-phosphate dehydrogenase-S protein distribution during mouse spermatogenesis. Biology of Reproduction 58 834-841.

Carrera A, Gerton GL \& Moss SB 1994 The major fibrous sheath polypeptide of mouse sperm: structural and functional similarities to the A-kinase anchoring proteins. Developmental Biology 165 272-284.

Carrera A, Moos J, Ning XP, Gerton GL, Tesarik J, Kopf GS \& Moss SB 1996 Regulation of protein tyrosine phosphorylation in human sperm by a calcium/calmodulin-dependent mechanism: identification of A kinase anchor proteins as major substrates for tyrosine phosphorylation. Developmental Biology 180 284-296.

Colledge M \& Scott JD 1999 AKAPs: from structure to function. Trends in Cell Biology 9 216-221. 
Cummins JM 1980 Decondensation of sperm nuclei of Australian marsupials: effects of air drying and of calcium and magnesium. Gamete Research 3 351-367.

Eddy EM 2007 The scaffold role of the fibrous sheath. Society of Reproduction and Fertility Supplement 65 45-62.

Eddy EM, Toshimori K \& O'Brien DA 2003 Fibrous sheath of mammalian spermatozoa. Microscopy Research and Technique 61 103-115.

Edwards AS \& Scott JD 2000 A-kinase anchoring proteins: protein kinase A and beyond. Current Opinion in Cell Biology 12 217-221.

Fulcher KD, Mori C, Welch JE, O'Brien DA, Klapper DG \& Eddy EM 1995 Characterization of Fsc1 CDNA for a mouse sperm fibrous sheath component. Biology of Reproduction 52 41-49.

Harris MS \& Rodger JC 1998 Characterisation of fibrous sheath and midpiece fibre network polypeptides of marsupial spermatozoa with a monoclonal antibody. Molecular Reproduction and Development 50 461-473.

Harris MS \& Rodger JC 2005 Characterisation of an epitope shared by an acrosomal acrosin-like protein and the surface of tammar wallaby (Macropus eugenii) spermatozoa. Journal of Experimental Zoology 303 $713-721$.

Jassim A, Gillott DJ, al-Zuhdi Y, Gray A, Foxon R \& Bottazzo GF 1992 Isolation and biochemical characterization of the human sperm tail fibrous sheath. Human Reproduction 7 86-94.

Johnson LR, Foster JA, Haig-Ladewig L, VanScoy H, Rubin CS, Moss SB \& Gerton GL 1997 Assembly of AKAP82, a protein kinase A anchor protein, into the fibrous sheath of mouse sperm. Developmental Biology 192 340-350.

Kim Y, Adham IM, Haack T, Kremling H \& Engel W 1995a Molecular cloning and characterization of the bovine and porcine outer dense fibers cDNA and organization of the bovine gene. Biological Chemistry 376 431-435.

Kim YH, McFarlane JR, Almahbobi G, Stanton PG, Temple-Smith PD \& de Kretser DM $1995 b$ Isolation and partial characterization of rat sperm tail fibrous sheath proteins and comparison with rabbit and human spermatozoa using a polyclonal antiserum. Journal of Reproduction and Fertility 104 107-114.

Kim YH, de Kretser DM, Temple-Smith PD, Hearn MT \& McFarlane JR 1997 Isolation and characterization of human and rabbit sperm tail fibrous sheath. Molecular Human Reproduction 3 307-313.

Lin M \& Rodger JC 1999 Acrosome formation during sperm transit through the epididymis in two marsupials, the tammar wallaby (Macropus eugenii) and the brushtail possum (Trichosurus vulpecula). Journal of Anatomy 194 223-232.

Lin M, Harman A \& Rodger JC 1997 Spermiogenesis and spermiation in a marsupial, the tammar wallaby (Macropus eugenii). Journal of Anatomy 190 377-395.

Mandal A, Naaby-Hansen S, Wolkowicz MJ, Klotz K, Shetty J, Retief JD, Coonrod SA, Kinter M, Sherman N, Cesar F et al. 1999 FSP95, a testisspecific 95-kilodalton fibrous sheath antigen that undergoes tyrosine phosphorylation in capacitated human spermatozoa. Biology of Reproduction 61 1184-1197.

Mate KE \& Rodger JC 1991 Stability of the acrosome of the brush-tailed possum (Trichosurus vulpecula) and tammar wallaby (Macropus eugenii) in vitro and after exposure to conditions and agents known to cause capacitation or acrosome reaction of eutherian spermatozoa. Journal of Reproduction and Fertility 91 41-48.

Miki K, Willis WD, Brown PR, Goulding EH, Fulcher KD \& Eddy EM 2002 Targeted disruption of the Akap4 gene causes defects in sperm flagellum and motility. Developmental Biology 248 331-342.

Mohapatra B, Verma S, Shankar S \& Suri A 1998 Molecular cloning of human testis mRNA specifically expressed in haploid germ cells, having structural homology with the A-kinase anchoring proteins. Biochemical and Biophysical Research Communications 244 540-545.
Nipper RW, Jones BH, Gerton GL \& Moss SB 2006 Protein domains govern the intracellular distribution of mouse sperm AKAP4. Biology of Reproduction 75 189-196.

Ohno S 1967 Sex Chromosomes and Sex Linked Genes, Berlin: Springer.

Poole WE, Simms NG, Wood JT \& Lubulwa M 1991 Tables for age determination of the Kangaroo Island wallaby (tammar), Macropus eugenii, from body measurements. In CSIRO Division of Wildlife and Ecology, Technical Memorandum Number 32, Canberra.

Ricci M \& Breed WG 2001 Isolation and partial characterization of the outer dense fibres and fibrous sheath from the sperm tail of a marsupial: the brushtail possum (Trichosurus vulpecula). Reproduction 121 373-388.

Ricci M \& Breed WG 2005 Morphogenesis of the fibrous sheath in the marsupial spermatozoon. Journal of Anatomy 207 155-164.

Sambrook J, Fritsch EF \& Maniatis T 1989 Molecular Cloning - A Laboratory Manual (Second), Cold Spring Harbor, NY: Cold Spring Harbor Laboratory Press.

Schempp W \& Meer B 1983 Cytologic evidence for three human X-chromosomal segments escaping inactivation. Human Genetics 63 171-174.

Sidhu KS, Mate KE, Gunasekera T, Veal D, Hetherington L, Baker MA, Aitken RJ \& Rodger JC 2004 A flow cytometric assay for global estimation of tyrosine phosphorylation associated with capacitation of spermatozoa from two marsupial species, the tammar wallaby (Macropus eugenii) and the brushtail possum (Trichosurus vulpecula). Reproduction 127 95-103.

Sistina Y, Lin M, Mate KE, Robinson ES \& Rodger JC 1993 The unique stability of the marsupial sperm acrosomal membranes examined by unprotected freeze-thawing and treatment with the detergent Triton X-100. Reproduction, Fertility, and Development 5 1-14.

Temple-Smith PD 1994 Comparative structure and function of marsupial spermatozoa. Reproduction, Fertility, and Development 6 421-435.

Temple-Smith PD \& Bedford JM 1976 The features of sperm maturation in the epididymis of a marsupial, the brushtailed possum Trichosurus vulpecula. American Journal of Anatomy 147 471-499.

Turner RM, Johnson LR, Haig-Ladewig L, Gerton GL \& Moss SB 1998 An $\mathrm{X}$-linked gene encodes a major human sperm fibrous sheath protein, hAKAP82, Genomic organization, protein kinase A-RII binding, and distribution of the precursor in the sperm tail. Journal of Biological Chemistry 273 32135-32141.

Tyndale-Biscoe CH \& Renfree MB 1987 Reproductive Physiology of Marsupials, pp 124-171. New York: Cambridge University Press.

Vijayaraghavan S, Liberty GA, Mohan J, Winfrey VP, Olson GE \& Carr DW 1999 Isolation and molecular characterization of AKAP110, a novel, sperm-specific protein kinase A-anchoring protein. Molecular Endocrinology 13 705-717.

Wang PJ, McCarrey JR, Yang F \& Page DC 2001 An abundance of X-linked genes expressed in spermatogonia. Nature Genetics 27 422-426.

Wilcox SA, Toder R \& Foster JW 1996 Rapid isolation of recombinant lambda phage DNA for use in fluorescence in situ hybridization. Chromosome Research 4 397-398.

Williamson P, Fletcher TP \& Renfree MB 1990 Testicular development and maturation of the hypothalamic-pituitary-testicular axis in the male tammar, Macropus eugenii. Journal of Reproduction and Fertility $\mathbf{8 8}$ 549-557.

Received 8 August 2008

First decision 17 October 2008

Revised manuscript received 10 December 2008

Accepted 12 January 2009 